\title{
A produção de materiais didáticos para o ensino de línguas no Brasil: propostas, objetivos e autoria
}

\author{
Jane Beatriz Vilarinho dos Santos \\ UFG/IFB
}

\begin{abstract}
Resumo
Este estudo foi motivado por desafios enfrentados durante o processo de produção de um livro didático para o ensino de língua inglesa, em um contexto de educação profissional. Tal ação suscitou a necessidade de melhor conhecer elementos que permeiam e orientam a prática docente, tal como a produção de materiais. Assim, nesse ensaio, traço inicialmente um panorama das propostas de formação docente. Em seguida, relaciono os enfoques dados aos materiais didáticos com as abordagens de ensino-aprendizagem e, posteriormente, faço um breve levantamento bibliográfico de estudos sobre produção de materiais. $\mathrm{O}$ objetivo consiste em analisar as possíveis relações existentes entre essas propostas, de modo a compreender melhor os elementos que influenciam a ação docente, e a concepção de autoria na área.
\end{abstract}

Palavras-chave: ensino-aprendizagem de línguas, formação docente, material didático.

\begin{abstract}
This study is the result of a challenging process of writing an English course book for a professional educational context. This activity highlighted the importance of understanding some of the concepts that guide the teaching practice, such as producing teaching materials. Therefore, in this essay, I first present some teacher education proposals. Then, I relate teaching materials to language teaching methods and also present a survey of studies about language teaching materials produced in Brazil. The aim of this study is to analyze the possible relations between these concepts, in order to understand more clearly the elements that influence teachers' practice and the notion of authorship in this area.
\end{abstract}

Keywords: language teaching, teacher education, teaching materials.

\section{INTRODUÇÃO}

Após uma experiência de autoria de material, na qual elaborei um livro didático para um curso de Inglês de Formação Inicial e Continuada (FIC), voltado para atendimentos comerciais em nível básico no Instituto Federal de Brasília, surgiu a vontade e a necessidade de buscar mais conhecimento acerca dos estudos sobre produção de materiais de línguas no Brasil. O processo de elaboração desse material se constituiu para mim em um grande desafio 
e suscitou vários questionamentos acerca da formação docente e da preparação do professor para elaborar materiais que atendam às demandas de seu contexto de ensino-aprendizagem.

Ao tratar da formação docente e a relevância da pesquisa nesse contexto, Freire (2007, p. 29) aponta que a pesquisa é uma condição básica para o ensino e também para a formação docente:

Fala-se hoje, com insistência, no professor pesquisador. No meu entender o que há de pesquisador no professor não é uma qualidade ou uma forma de ser ou de atuar que se acrescente a ensinar. Faz parte da natureza da prática docente a indagação, a busca, a pesquisa. O que se precisa é que, em sua formação permanente, o professor se perceba e se assuma, porque professor, como pesquisador.

Essa visão reforçou os questionamentos que motivaram esse estudo, dentre os quais destaco o seguinte: As propostas de formação de professores contemplam a constituição de um profissional autônomo que se sinta apto a produzir materiais, pesquisas, ou seja, conhecimento de modo geral? Dúvidas como essa revelaram a necessidade de buscar informações acerca das propostas de formação docente e de produção de materiais didáticos no Brasil. Assim, o objetivo desse estudo consiste em fazer um levantamento dos papéis historicamente desempenhados por nós professores de línguas ou a nós atribuídos, e dos estudos sobre materiais didáticos no Brasil, discutindo seu enfoque, no intuito de melhor compreender o nosso papel de professor e a autonomia que temos na atualidade.

Nesse intuito, desenvolvemos aqui um ensaio com base em artigos de revistas científicas e livros produzidos por outros pesquisadores. Iniciamos, então, nosso estudo com uma breve cronologia das características do papel do professor descritas na bibliografia da área. Em seguida, destacamos alguns enfoques dados aos materiais didáticos produzidos no Brasil, tendo em vista suas concepções de ensino-aprendizagem e, posteriormente, destacamos alguns estudos sobre material didático desenvolvidos em nosso país. Por fim, buscamos traçar uma relação entre as propostas de formação de professores e a realidade dos estudos sobre materiais didáticos de línguas, embasando-nos em elementos como autoria e produção de conhecimento na Linguística Aplicada.

\section{PROPOSTAS DE FORMAÇÃO DOCENTE}

Até o século 20, segundo Gómez (1997), o processo de formação de professores se baseava em uma visão positivista, em que o professor era visto como aplicador de técnicas e 
solucionador de problemas de sua prática profissional. Schön (1987), contudo, ressalta que a prática docente envolve muito mais que tarefas práticas, e por isso, logo nas décadas de 1970 e 1980, o entendimento do pesquisador como produtor de conhecimento que guia a prática docente, e do professor como consumidor de tal conhecimento e aplicador de técnicas entra em crise.

O questionamento sobre a relevância da relação entre os saberes recebidos na formação de profissionais de diversas áreas e a sua prática dá origem, então, a um novo modelo de formação - o do profissional reflexivo, proposto por Schön (1983, p. 49). Nesse modelo, proposto não especificamente para docentes, mas para profissionais de um modo geral, o autor propõe que seja considerado o conhecimento do profissional, ao contrário do que era proposto na racionalidade técnica. Assim, o autor propõe "buscar, ao contrário, uma epistemologia da prática implícita nos processos artísticos e intuitivos que alguns profissionais trazem para as situações de incerteza, instabilidade, singularidade e conflito de valores".

Referindo-se à formação docente, Borelli (2006, p. 35) afirma que essa "nova proposta de formação profissional requer uma reconceitualização sobre o que é ser professor, seus saberes e sua prática", pois considera o conhecimento tácito do profissional, denominado por Schön (1983) como "conhecimento-na-ação". Essa nova proposta de formação centra-se, assim, na reflexão como instrumento de identificação, análise e solução de questões da realidade docente. Dewey (1953, p. 22) destaca também que o pensamento reflexivo possui um objetivo e por isso motiva a busca, a pesquisa que

diferentemente das outras operações a que se dá o nome de pensamento, abrange: (1) um estado de dúvida, hesitação, perplexidade, dificuldade mental, o qual dá origem ao ato de pensar; e (2) um ato de pesquisa, procura, inquirição, para encontrar material que resolva a dúvida, assente e esclareça a perplexidade.

Ao tratar sobre reflexão, Schön (1983) a organiza em dois tipos: reflexão-na-ação e reflexão-sobre-a-ação. A primeira ocorre no momento da prática, e a segunda, antes ou após o momento da prática docente. Com a proposta de formação de profissionais reflexivos, há então uma grande mudança no papel do professor que deixa de ser mero aplicador de técnicas e transmissor de conhecimentos desenvolvidos pelos pesquisadores, para assumir uma postura de pesquisador da própria prática e de produtor de conhecimento. Schön (1983, p.68), então, destaca que "[...] quando alguém reflete-na-ação, ele se torna um pesquisador no contexto da 
prática. Ele não depende das categorias da teoria e técnica estabelecidas, mas constrói uma nova teoria de um caso particular".

A proposta de reflexão apresentada por Schön (1983) traz, segundo Zeichner e Liston (1996), uma nova concepção de conhecimento e também da relação teoria e prática, contudo, deixa de lado a dimensão dialógica e discursiva do ensino. Por isso, os autores propõem um conceito de formação em que o contexto social seja valorizado e no qual a reflexão seja feita por meio do diálogo e não de modo individual - motivando, então, a proposta de reflexão crítica e colaborativa.

Ao abordar a prática crítico-reflexiva, Zeichner e Liston (1996) retomam o estudo de Solomon (1987), para demonstrar que, sem a reunião de um grupo, ou seja, um corpo social para a discussão de suas ideias, o desenvolvimento do professor é inibido, pois essas ideias se tornam mais claras ao falarmos com o outro. Os autores reforçam ainda a importância do estabelecimento de um ambiente de colaboração, como o sugerido por Osterman e Kottkamp (1993), para que o professor consiga desenvolver uma consciência crítica sobre suas próprias ações. Essa prática teria como elemento base a confiança entre os participantes, sem a qual a reflexão sobre suas práticas seria essencialmente limitada.

Logo, Zeichner e Liston (1996) propõem que o processo de reflexão crítica dos professores não tenha como seu único foco as suas próprias práticas, mas também as condições sociais que as envolvem: "se eles vão se tornar professores reflexivos e não professores técnicos, então, eles devem procurar manter uma ampla visão sobre seu trabalho e não apenas internamente sobre suas práticas" (p. 19).

Smyth (1991), por sua vez, destaca que a reflexão crítica traz maior autonomia ao docente, já que, nessa proposta, o pensamento e a ação, a teoria e a prática, e o trabalho mental e o manual não são vistos como dissociados. Desse modo, por ser o professor um importante agente desse contexto, entende-se que ele mesmo deve refletir a respeito dos elementos e necessidades da realidade de ensino-aprendizagem que vivencia, ou seja, que tenha autonomia. Nesse estudo entendemos por autonomia a emancipação e consciência crítica, que dá ao profissional a possibilidade de superação das opressões sociais e ideológicas de sua realidade, visando então à transformação dessa realidade (CONTRERAS, 2002).

Atualmente, tem-se por objetivo a formação de educadores autônomos, capazes de refletir criticamente sobre suas ações e transformá-las. Embora muitos estudos da área de Formação de Professores tenham se embasado na reflexão, as tentativas de formar 
profissionais críticos tem enfrentado diversos percalços, dentre os quais temos a separação entre a teoria e a prática. Magalhães (2004) ressalta que em nenhum desses extremos, contudo, o professor recebe apoio para compreender e conscientizar-se sobre os elementos que embasam suas escolhas e ações, não sendo, portanto, capaz de refletir criticamente e/ou reconstruir suas práticas.

Vemos então que com base nas demandas históricas do contexto de ensinoaprendizagem de línguas, diferentes propostas de formação docente foram estruturadas e implementadas. Liberali (2004), ao tratar da formação docente, retoma os níveis de reflexão propostos por Van Manen (1977, apud LiBERALI, 2004), a fim de destacar os tipos de educadores que poderiam ser formados. O autor categoriza a reflexão em três tipos: a reflexão técnica, a reflexão prática e a reflexão crítica. A reflexão técnica restringe-se a análise de elementos técnicos relativos ao ensino-aprendizagem que permite ao professor prever e controlar os eventos em sala de aula. "Sua maior preocupação seria a eficiência e eficácia dos meios para atingir determinados fins, sendo que esses fins não estariam abertos à crítica ou à mudança” (LIBERALI, 2004, p. 88).

A reflexão prática aprofunda a análise dos dados, pois considera os objetivos da aula, bem como as suposições subjacentes a estes objetivos e seus resultados. "A reflexão prática está relacionada aos problemas da ação que não são passíveis de serem resolvidos apenas de forma instrumental. Interessa aqui o conhecimento que facilita o entendimento e o alcance do entendimento com os outros" (LiBerALI, 2004, p. 89). Segundo Romero (1998, apud LIBERALI, 2004), este tipo de reflexão abrange o entendimento interpessoal bem como a interpretação de práticas sociais. E por último, tem-se a reflexão crítica, que engloba os fatores analisados nas anteriores e acrescenta os critérios morais que permeiam tal contexto. Liberali (2004, p. 89), destaca que “[...] nesse nível, as questões ponderam sobre objetivos educacionais, experiências e atividades levam a formas de vida preocupadas com a justiça, igualdade e realizações concretas".

A partir dos três critérios de reflexão apresentados, observamos que três tipos de educadores podem ser formados. Para Van Manen (1997, apud LIBERALI, 2004) estes são: o educador técnico preocupado em alcançar os objetivos ditados por outros, o educador prático para o qual são relevantes as justificativas educacionais que subjazem às suas práticas e a qualidade dos objetivos atingidos, e o educador crítico que abordaria as implicações éticas e morais de suas ações, avaliando sua posição como membro de uma instituição. 
Acreditamos que, assim como as propostas de formação docente, a produção de materiais didáticos no Brasil também tenha sofrido influências históricas, sociais e também de outras teorias da época. Assim, para desvelarmos tal realidade, a seguir, tecemos um breve histórico do enfoque dado aos materiais didáticos produzidos no Brasil, a fim de que possamos então relacioná-los com as teorias pertinentes, tal como a formação docente.

\section{O ENFOQUE DO MATERIAL DIDÁTICO NO BRASIL}

Para discutir o enfoque dos materiais didáticos no Brasil, recorremos ao texto História do Material Didático de Língua Inglesa no Brasil de Paiva (2009), pois, embora nosso estudo aborde línguas de modo geral, acreditamos que esse traz um panorama atual sobre os estudos da área e importantes considerações que podem ser também aplicadas a outras línguas. Sobre a escolha do material didático, a autora ressalta que a sua escolha se dá, inicialmente, em virtude da disponibilidade do material, independentemente da sua metodologia de ensino. Por isso, Paiva (2009, p. 19) ressalta que "era comum, até o final do século 18 , encontrar uma sala de aula em que os alunos possuíam livros diferentes".

A autora aponta que o primeiro livro didático foi a gramática, cujo conceito de língua era o de estrutura gramatical, e que a primeira indicação de autoria de um livro se deu em 1578 em uma gramática do hebraico. E assim como o uso de qualquer ferramenta educacional, o uso do livro em sala de aula foi polêmico e controverso. A popularização do livro, segundo a autora, ocorreu juntamente com a popularização do método gramática e tradução. Nesse período, o objetivo dos livros era trazer frases, listas de vocabulários e tópicos gramaticais da língua-alvo com níveis de dificuldades crescentes.

Apenas no final da década de 40, a ênfase na habilidade escrita da língua é transferida para a oralidade, e o conteúdo passa a ser todo ministrado na língua-alvo. Desse modo, a tradução é substituída por ilustrações que podem auxiliar na compreensão do aluno. Já "na década de 1970, surgem os materiais audiovisuais (...) que ressuscitavam a mesma desconfiança com o texto escrito do século 19 e davam primazia à oralidade" (PAIVA, 2009, p. 35). Nesse período, era então papel do professor auxiliar o aluno a desenvolver a compreensão oral, enfatizando atividades auditivas e retardando atividades de leitura, pois acreditava-se que o contato com a escrita seria negativo no processo de aquisição de línguas. 
Até a década de 1970, a produção de materiais foi influenciada pela Abordagem Tradicional/Estruturalista, ou seja, aquela baseada no conceito de língua como sistema de regras. A partir desse período, com o destaque da Abordagem Comunicativa, há uma grande produção de materiais para fins específicos (atendimento comercial, finanças, turismo etc.). Produção essa que aumentou com o advento do mercantilismo, a proposta de universalização do ensino e o avanço tecnológico que, como destacam Pessoa e Borelli (2011, p. 09), "permitiu a produção de material didático cada vez mais sofisticado e em grande escala, alterando novamente as condições de trabalho do professor e transformando-o em um técnico responsável por controlar a aprendizagem".

E ainda no que se refere ao professor e ao material didático, Paiva (2009) salienta a diversidade de materiais que hoje o professor tem à sua disposição, os quais contemplam principalmente duas abordagens: a tradicional/estrutural e a comunicativa. E ainda acrescenta:

\footnotetext{
Apesar da imensa quantidade de materiais e de todos os recursos gratuitos na web, esperase que o professor seja capaz de adaptar e complementar o livro adotado, e, até mesmo, de produzir material didático para seu contexto específico (PAIVA, 2009, p. 53).
}

Vemos, assim, que apesar do desenvolvimento dos estudos em Linguística Aplicada, no que se refere à relação teoria e prática, ou seja, produção e aplicação de conhecimento, o que ainda parece ser esperado do professor é uma atuação ou uma reflexão mais técnica ou prática (VAN MANEN, 1977, apud LIBERALI, 2004). A produção de conhecimento já seria algo além de sua ação, pois ao dizer até mesmo, a autora nos dá a ideia da realização de algo que não seria inerente a sua prática. Não é nosso intuito aqui emitir nenhum juízo de valor sobre o estudo da autora, o qual é de grande contribuição para a área, queremos apenas destacar o estranhamento que ainda temos ao nos referir ao professor como produtor de conhecimento, de materiais etc.

Notamos também que, baseadas nas necessidades dos contextos de ensinoaprendizagem de línguas e na realidade histórica e social de cada época, distintas propostas de materiais didáticos foram elaboradas, como mostrou Paiva (2009), motivadas pelas Abordagens Tradicional/Estruturalista e Comunicativa, que impulsionaram o ensino de línguas no Brasil. Na Abordagem Tradicional/Estruturalista, os métodos tinham influência das ciências comportamentais, e assim entendiam o aprendizado como formação de hábitos e por isso os erros deviam ser evitados.

Sobre a Abordagem Estruturalista, Figueiredo e Oliveira (2012) destacam que essa prioriza a forma e estrutura da língua e orienta os métodos gramática e tradução, e 
audiolingual. Os autores acrescentam também que nesses métodos, as técnicas comuns são: "a tradução de orações e de itens lexicais, exercícios de transformação de sentenças, de repetições e substituições de palavras, entre outras" (p. 13).

Já na Abordagem Comunicativa, como o próprio nome indica, a aprendizagem tem por objetivo a comunicação. Figueiredo e Oliveira (2012, p. 13) apontam que essa abordagem "prioriza o significado da mensagem, o propósito comunicativo das interações" e tem como técnica recorrente o trabalho em pares. Percebemos, então, que o foco anteriormente colocado na estrutura linguística na Abordagem Tradicional/Estrutural é, na Abordagem Comunicativa, deslocado para o processo de comunicação em si. Os autores ressaltam ainda que essa abordagem influenciou o surgimento de outras que priorizavam a comunicação, tais como a Abordagem Colaborativa e a Abordagem Baseada em Tarefas (FIGUEIREDO E OLIVEIRA, 2012).

Como vemos, as propostas de ensino-aprendizagem de línguas, de formação docente no que se refere ao papel do professor, e as de materiais didáticos se entrecruzam, ou se influenciam mutuamente. Assim, para melhor entendermos a realidade do material didático no contexto brasileiro, apresentamos a seguir alguns estudos desenvolvidos sobre esse assunto.

\section{OS ESTUDOS SOBRE MATERIAIS DIDÁTICOS NO BRASIL}

Alguns estudos como os de Paiva (2009), Souza (2011), Coracini (2011) tratam em específico do livro didático, o qual ainda se constitui como um dos principais materiais didáticos utilizados em sala de aula. Já outros como os de Scheyerl (2012), Rajagopalan (2012) e Pereira (2013) abordam o material didático de modo mais abrangente. Coracini (2011) evidencia que os estudos sobre material didático se intensificaram a partir de 2011, pois, apesar da preocupação da Linguística Aplicada com o processo de ensino-aprendizagem de línguas e da relevância do material didático nesse processo, os linguistas aplicados não haviam lhe concedido até então grande espaço em estudos da área.

Ao fazermos um levantamento de estudos sobre o tema, notamos que alguns estudiosos já se ocupavam da questão do material didático antes de 2011, dentre eles temos: Cristóvão (2005), Dourado (2008), Tílio (2008), Figueredo (2009) e Pessoa (2009). A seguir, detalhamos os dois últimos para que tenhamos uma ideia das discussões que perpassavam esse tema. 
Figueredo (2009) realiza um estudo em parceria com uma professora de uma escola pública municipal de Goiânia e dois bolsistas para produção de materiais didáticos, com base na abordagem intercultural, para o ensino de inglês para alunos do ciclo 2. Sobre os resultados desse estudo, a autora avalia que o material produzido foi satisfatório, o conhecimento de língua-cultura da língua materna e também da língua alvo foram enfatizados e ampliados pelos alunos, e isso não interferiu no desenvolvimento da competência linguística dos alunos.

Já Pessoa (2009), no artigo intitulado "O livro didático na perspectiva da formação de professores", baseada em um conceito de língua como prática social, problematiza a adoção do livro didático, relacionando o amplo uso do mesmo ao papel de aplicador de técnicas, por vezes, atribuído ao professor. Nesse sentido, a autora questiona: "No entanto, nos modelos atuais de formação, que objetivam principalmente que os professores construam conhecimento sobre ensino e aprendizagem, será que há espaço para o livro didático ou deveria o professor criar seus próprios materiais? (p. 53)”. Após suas reflexões, a autora relata que o livro didático se fez necessário para a prática de seus participantes, professores iniciantes, os quais ao mesmo tempo destacaram como positiva a experiência que tiveram como alunos num curso em que livros didáticos não eram adotados. Desse modo, a autora conclui que a profissionalização e experiência docente pode dar aos docentes mais autonomia para atuar e produzir seus materiais.

Notamos, assim, que elementos como o papel do professor e a produção de materiais já abordados por Figueredo (2009) e Pessoa (2009) ainda ocupam a agenda de estudos da área. E, ao contrário do que postula Pessoa (2009), Coracini (2011) em seu estudo vem destacar a importância do livro didático no contexto brasileiro. Nesse intuito, Coracini (2011) retoma Molina (1987) e apresenta que os "livros dos cursos fundamental e médio constituem $33,5 \%$ do total de livros produzidos no país, perfazendo um total de $99 \%$ do mercado editorial brasileiro" (p. 17). Desse modo, a autora pondera que tendo em vista sua importância para o mercado editorial, bem como para o ensino-aprendizagem de línguas, a esse tema deveriam ser direcionados mais reflexões e estudos. Contudo, segundo Souza (2011), conforme levantamento em revistas da área, tais como Trabalhos de Linguística Aplicada, D.E.L.T.A., ESPecialist, Contexturas e Intercâmbio, poucos estudos se dedicavam a uma análise detalhada de livros didáticos, e ressalta ainda que "a maior parte deles apresentam, na introdução, uma menção crítica ao LD em geral e, em seguida, propõem critérios para a escolha do material, estratégias e técnicas de ensino da língua estrangeira ou materna que sejam motivadoras e comunicativas" (p. 18). 
A autora salienta, então, que boa parte dos estudos limita-se a demonstrar a inadequação do material didático adotado para determinado público alvo, ou então, devido à influência da Abordagem Comunicativa, a destacar a importância de não se adotar um livro didático e de trabalhar com textos autênticos de áreas diversas: história, geografia, ciências, de modo a atender aos interesses dos alunos e a fazer o uso de língua em um contexto real.

Os papéis de professor e autor estão, em grande parte, para Coracini (2011) dissociados. Os autores, representados por editoras, fazem pesquisas de opinião junto a professores e alunos a fim de verificar quais os melhores materiais, e esses tendem a coincidir com os mais vendidos, o que faz com que se complete o ciclo de (re)produção de materiais e metodologias de ensino, conforme pontua Coracini (2011). A autora acrescenta ainda que se

num congresso de professores de língua estrangeira, pesquisadores apresentam seus trabalhos ao mesmo tempo em que, noutra sala, representantes de editoras apresentam "novos" livros didáticos, os primeiros perdem de longe para os segundos, tal é o interesse que estes despertam (Coracini, 2011, p. 21).

Em seguida, Coracini ressalta a possibilidade de o professor produzir material didático para o seu contexto, porém reforça que o que se constata, "na maior parte das vezes, é a repetição das mesmas maneiras de proceder do livro didático" (p. 24).

Essa dificuldade do professor em modificar ou adaptar atividades do livro didático é não apenas apontada, mas justificada por Souza (2011), no texto "Autoridade, autoria e livro didático", ao discutir o valor social atribuído ao livro didático e ao autor, afirmando que

[...] o caráter de autoridade do livro didático encontra sua legitimidade na crença de que ele é depositário de um saber a ser decifrado, pois supõe-se que o livro didático contenha uma verdade sacramentada a ser transmitida e compartilhada. Verdade já dada que o professor, legitimado e institucionalmente autorizado a manejar o livro didático, deve apenas reproduzir, cabendo ao aluno assimilá-la.

"Verdade" essa que precisa ser problematizada e reconstruída pelo professor. É importante que nós professores tenhamos a oportunidade de conhecer os processos sociais e históricos pelos quais as ideias, as estruturas sociais e os modos de trabalho foram formados. Tal conhecimento pode nos auxiliar a compreender o contexto no qual estamos inseridos e aqueles que influenciaram a produção dos materiais didáticos de que fazemos uso. E que assim possamos identificar e/ou reconhecer o nosso papel no processo de ensinoaprendizagem e em nosso processo de formação docente. Sabemos, contudo, que estas não se constituem em tarefas fáceis, pois envolvem questionamentos de nossos valores, crenças e saberes, o que influencia nossa rotina de sala de aula e também nossa autoestima. 
Vemos, sobretudo, que, para a autora, os papéis do produtor de conhecimentos e do professor estão separados, cabendo ao primeiro a realização de pesquisas e a produção de materiais, e ao segundo, a sua aplicação. Acreditamos, no entanto, que a realidade de produção de conhecimentos já começa a ser modificada nos estudos da Linguística Aplicada, tendo em vista que vários professores, estudiosos da área, tem assumido o papel de pesquisador e/ou trabalhado colaborativamente em pesquisas com outros docentes, de modo a intervir e transformar seus contextos de ensino-aprendizagem. Dentre esses estudos podemos citar os de Silvestre (2011), Ribeiro (2011), Pessoa e Borelli (2011), Sabota (2012), Figueiredo (2012), Pessoa e Urzeda-Freitas (2012), Pereira (2013) etc. E no que se refere à produção de materiais didáticos, como vimos, podemos destacar os estudos das professoras Figueredo (2009) e Pessoa (2009).

Ao tratar sobre materiais didáticos, é preciso levar em conta não apenas elementos do material em si, mas todos os agentes e contexto de produção. A esse respeito, Rajagopalan (2012) discute o caráter eminentemente político das línguas, principalmente as hegemônicas, tais como: o inglês, o francês e o espanhol e suas representações em livros didáticos de ensino-aprendizagem. Segundo o autor, esses materiais para ensino de línguas ainda são utilizados "para fins propagandísticos ou, no mínimo questionáveis do ponto de vista ideológico" (p. 77). Assim, o autor destaca a necessidade urgente de que os textos dos materiais didáticos não sejam vistos como neutros, a fim de que possam ser ideologicamente questionados e não apenas reforcem ou reproduzam uma ideologia.

Pereira (2013, p. 117), por sua vez, desenvolve no doutorado um estudo sobre as representações de gênero em livros didáticos produzidos no Brasil para o ensino de inglês. Nesse estudo, o autor analisa a sala de aula como local de "produção, reprodução e resistência às relações sociais entre gêneros" e também os discursos presentes nos livros. E a esse respeito conclui que, no geral, os livros são constituídos por discursos de várias linhas ideológicas e mesmo quando dizem trazer uma visão vanguardista de sociedade, apresentam elementos ou aspectos conservadores. Desse modo, Pereira (2013, p. 142-143) ressalta a importância de que os textos sejam criticamente analisados e discutidos com os alunos de modo que não reforcem visões hegemônicas, por isso diz:

As ideias e valores expressos nas representações de gênero e outras categorias sociais têm forte influência na produção e reprodução dos discursos por elas veiculados, discursos esses que, na maioria das vezes, não são contestados ou desafiados, mas reforçados e legitimados nas interações entre sujeitos e textos de livros didáticos, na sala de aula. 
Destacamos aqui nessa seção alguns estudos sobre material didático, realizados na área de Linguística Aplicada, no Brasil, desde 2009 até os dias atuais. E com base no levantamento e análise feitas desses dados apresentamos a seguir algumas reflexões e considerações acerca de tema, relacionando-o com as propostas para formação docente, relação essa que nos motivou a discutir produções de conhecimentos, tal como a autoria ou produção de material didático.

\section{REFLEXÕES SOBRE O TEMA E CONSIDERAÇÕES FINAIS}

Ao analisarmos os estudos de formação de professores, notamos que, desde a década de 1980, com a proposta de formação de professores reflexivos já há a proposta de que os professores reassumam o seu papel de produtores de conhecimento. Desse modo, nesse período já encontramos o questionamento do binômio teoria e prática, colocando em pauta a produção de conhecimento, pesquisas e materiais por agentes externos ao contexto de ensinoaprendizagem, e a atribuição do professor de realizar uma atividade mais prática de aplicação de métodos e técnicas.

Contudo, apesar do desenvolvimento dos estudos em Linguística Aplicada, verificamos que, por vezes, esse binômio ainda permanece, tal como relatado por Coracini (2011). É importante ressaltar, no entanto, que muito já tem sido feito no intuito de auxiliar o professor nesse processo de formação e autonomia para que esse possa atender às demandas e intervir em sua realidade, por meio de análises e pesquisas sobre materiais didáticos como percebemos nos estudos de Figueredo (2009), Pessoa (2009) Pereira (2013), Rajagopalan (2012), dentre outras. Grande contribuição é também dada pelo estudo de Coracini (2011), pois, ao descrever o funcionamento do contexto de produção de materiais do Brasil, a autora contribui para que os leitores e estudiosos da área, cientes de tal realidade, possam problematizá-la, motivando, assim, reflexões e intervenções.

Como pontuamos anteriormente, Souza (2011) ressalta que a dificuldade do professor intervir no material ou livro didático advém do valor social a ele atribuído. Desse modo, enfrenta barreiras para assumir-se como produtor de conhecimentos, pesquisador e autor, dificuldades essas que resultam não apenas do desprestígio profissional dessa função, em alguns contextos, mas também de elementos sociais e históricos. Vimos que, ao longo dos tempos, o professor tem assumido diversas funções, e ao discutir essas representações sociais de professores sobre o que é ser professor, Braúna e Reis $(2013$, p. 66) destacam que 
[...] a indefinição das funções do professor torna mais difusa a concretização de sua identidade e de seu sentido. Diante dessa diversidade de tarefas, os professores têm dificuldades em definir e delimitar objetivos e prioridades em sua atividade profissional, e essa situação tem contribuído com a vivenciada na atualidade pelos professores.

Como demonstram as autoras, a diversidade e distinção de demandas historicamente colocadas ao professor dificultaram a constituição da identidade desse profissional e, de certo modo, contribuíram para que ele assumisse cada vez mais o papel de "espectador" no processo de ensino-aprendizagem. O professor não tem bem definidas as suas atribuições e vê as decisões relativas ao seu contexto de trabalho, tais como metodologia de ensino a ser utilizada, a organização do currículo, tipo de avaliação a ser aplicada, a seleção/produção de material a ser adotado, dentre outras, serem tomadas por agentes externos, logo, percebe-se com pouca autonomia.

Notamos, assim, que as propostas de ensino-aprendizagem, de formação docente e de materiais didáticos no Brasil estão diretamente relacionadas, se informam mutuamente e são igualmente complexas, pois são determinadas por um contexto social e ideológico. A complexidade do material didático se torna clara nesse estudo ao verificarmos a diversidade de aspectos abordados em estudos sobre o tema que, como vimos, têm sido propostos na área: Figueredo (2009) discute a produção de materiais didáticos para o ensino fundamental com base em uma abordagem intercultural, Pessoa (2009) problematiza a relevância do livro didático em um contexto de formação de professores autônomos e produtores de conhecimento, Rajagopalan (2012) e Pereira (2013) destacam o caráter ideológico do material didático e ressaltam a importância da problematização dos textos e dados ali contidos, de modo que o livro não reproduza ou reforce visões hegemônicas.

Acreditamos que o empoderamento do professor como produtor de conhecimento, pesquisas e materiais didáticos possa ser o caminho para a transformação social e para uma educação mais igualitária e crítica. Uma realidade educacional em que professores e alunos atuem colaborativamente na construção do conhecimento e em que docentes desenvolvam estudos que atendam as demandas de seus contextos.

Cientes, por fim, dos desafios da área, esperamos que esse estudo auxilie os docentes de línguas e outros possíveis leitores a conhecer melhor a realidade de formação docente e de produção de material didático no Brasil. Almejamos também que tal ciência traga aos docentes de línguas maior autonomia, ou seja, consciência crítica a fim de que possam superar 
as opressões sociais e ideológicas do seu contexto de atuação, das propostas de ensinoaprendizagem, das propostas de formação docente e também do material didático.

\section{REFERÊNCIAS}

BORELLI, J. D. V. P. Reflexão colaborativa sobre teoria e prática: uma experiência de formação com quatro professoras de inglês. Dissertação de mestrado em Estudos Linguísticos. Faculdade de Letras, Universidade Federal de Goiás, Goiânia, 2006.

BRAÚNA, R. C. de. A.; REIS, A. C. de L. Representações sociais de professoras sobre o ser professor: dimensões da profissionalidade. In: BRAÚNA, R. C. de A.; BARCELOS, A. M. F. (Ed.). Demandas contemporâneas na formação de professores, Viçosa: Editora UFV, 2013, p. 64-79.

CORACINI, M. J. R. F. O livro didático nos discursos da linguística aplicada e da sala de aula. In: CORACINI, M. J. (org.) Interpretação, autoria, e legitimação do livro didático, Campinas: Pontes, 2011, p. 17-26.

CONTRERAS, J. A autonomia de professores. São Paulo: Cortez, 2002.

DEWEY, J. Como pensamos. São Paulo: Companhia Editora Nacional, 1953.

FIGUEREDO, C. J. A produção de materiais didáticos para o ensino de língua inglesa como LE no ciclo 2 a partir de uma abordagem intercultural. Anais do SILEL, vol. 1. Uberlândia: EDUFU, 2009.2 Disponível em: http://www.ileel2.ufu.br/anaisdosilel/pt/edicao_volume_1_numero 1.php. Acesso em: $30 \mathrm{de}$ agosto, 2014.

FIGUEIREDO, J. Q. Erro escrito e formas de correção. In: FIGUEIREDO, F. J. Q (Org.). Formação de Professores de línguas estrangeira: princípios e práticas, Goiânia: Editora UFG, 2012, p. 158-175.

FIGUEIREDO, J. Q.; OLIVEIRA, E. C. Sobre métodos, técnicas e abordagens. In: FIGUEIREDO, F. J. Q (Org.). Formação de Professores de línguas estrangeira: princípios e práticas. Goiânia: Editora UFG, 2012, p. 11-40.

FREIRE, P. A pedagogia da autonomia. São Paulo: Paz e Terra, 2007.

GÓMEZ, A. P. O pensamento prático do professor: a formação do professor como profissional reflexivo. In: NÓVOA, A. (coord.) Os professores e sua formação, Lisboa: Publicações Dom Quixote, 1997, p. 77-91.

LIBERALI, F. C. As linguagens das reflexões. In: MAGAlHÃES, M. C. C. (Org.) A formação do professor como um profissional crítico, Campinas: Mercado de Letras, 2004, p. $87-117$. 
MAGALHÃES, M. C. C. As linguagens na formação de professores como profissionais reflexivos e críticos. In: MAGALHÃES, M. C. C. (Org.) A formação do professor como um profissional crítico, Campinas: Mercado de Letras, 2004, p. 59-86.

OSTERMAN K.; KOTTKAMP, R. Reflective practice for educators. Newbury Park, CA: Corwin Press, 1993.

PAIVA, V. L. M. O. História do material didático de língua inglesa no Brasil. In: DIAS, R.; CRISTOVÃO, V. L. L. (Orgs.). O livro didático de língua estrangeira - múltiplas perspectivas, Campinas: Mercado de Letras, 2009, p. 17-56.

PEREIRA, A. L. Representações de gênero em livros didáticos de língua estrangeira: discursos gendrados e suas implicações para o ensino. In: PEREIRA, A. L.; GOTTHEIM, L. (Org.). Materiais didáticos para o ensino de língua estrangeira - processos de criação e contextos de uso, Campinas: Mercado de Letras, 2013, p. 113-146.

PESSOA, R. R. O livro didático na perspectiva da formação de professores. Trabalhos de Linguística Aplicada, vol.48, n.1, Campinas Jan./June 2009, p. 53-69.

PESSOA, R. R., BORELLI, J. D. V. P. Linguística aplicada e formação de professores: convergências da atuação crítica. In: PESSOA, R. R., BORELLI, J. D. V. P. (Org.) Reflexão e crítica na formação de professores de língua estrangeira, Goiânia: Editora UFG, 2011, p. 15-30.

PESSOA, R. R; URZEDA-FREITAS, M. T. Ensino crítico de línguas estrangeiras. In: FIGUEIREDO, F. J. Q. (Org.) Formação de professores de línguas estrangeiras: princípios e práticas, Goiânia: Editora UFG, 2012, p. 57-80.

RAJAGOPALAN, K. O papel eminentemente político dos materiais didáticos de inglês como língua estrangeira. In: SCHEYERL, D.; SIQUEIRA, S. Materiais didáticos para o ensino de línguas na contemporaneidade: contestações e proposições, Salvador: Editora da UFBA, 2012, p. 57-82.

RIBEIRO, S. A. Fontes de aprendizagem docente: uma investigação com uma professora de inglês da escola pública. In: PESSOA, R. R., BORELLI, J. D. V. P. (Org.) Reflexão e crítica na formação de professores de língua estrangeira, Goiânia: Editora UFG, 2011, p. 127144.

SABOTA, B. Leitura e compreensão textual. In: FIGUEIREDO, F. J. Q. (Org.) Formação de professores de línguas estrangeiras: princípios e práticas, Goiânia: Editora UFG, 2012, p. 118-135.

SCHEYERL, D. Práticas ideológicas na elaboração de materiais didáticos para a educação linguística. In: SCHEYERL, D.; SIQUEIRA, S. Materiais didáticos para o ensino de línguas na contemporaneidade: contestações e proposições, Salvador: Editora da UFBA, 2012, p. 37-56.

SCHÖN, D. The reflective practitioner. New York: BasicBooks, 1983. 
SCHÖN, D. Educating the reflective practitioners. San Francisco: Jossey-Bass, 1987.

SILVESTRE, V. P. V. Problematização da prática: momentos críticos de uma aula de inglês. In: PESSOA, R. R., BORELLI, J. D. V. P. (Org.) Reflexão e crítica na formação de professores de língua estrangeira, Goiânia: Editora UFG, 2011, p. 81-94.

SMYTH, J. Teachers as collaborative learners: challenging dominant forms of supervision. Buckingham: Open University Press, 1991.

SOUZA, D. M. Autoridade, autoria e livro didático. In: CORACINI, M. J. (org.) Interpretação, autoria, e legitimação do livro didático. Campinas: Pontes, 2011, p. 27-32.

ZEICHNER, K. M.; LISTON, D. P. Reflective teaching: an introduction. New Jersey: Lawrence Erlbaum Associates, Inc., Publishers, 1996.

\section{A AUTORA}

Jane Beatriz Vilarinho dos Santos é aluna de doutorado em Linguística da Faculdade de Letras da Universidade Federal de Goiás (UFG) e docente do quadro efetivo de língua inglesa do Instituto Federal de Brasília (IFB).

E-mail: jbvilarinho@gmail.com 